\title{
Design and Construction of Zana Robot for Modeling Human Player in Rock-paper-scissors Game using Multilayer Perceptron, Radial basis Functions and Markov Algorithms
}

\author{
Maryam Ghasemi ${ }^{1}$, Abdolreza Roshani ${ }^{2}$, Peshawa J. Muhammad Ali ${ }^{3}$, Farhad F. Nia ${ }^{1}$, \\ Ehsan Nazemi ${ }^{4}$ and Gholam H. Roshani ${ }^{1}$ \\ ${ }^{1}$ Department of Electrical Engineering, Faculty of Energy, Kermanshah University of Technology, \\ Kermanshah, Iran \\ ${ }^{2}$ Department of Industrial Engineering, Faculty of Engineering Management, Kermanshah University of Technology, \\ Kermanshah, Iran \\ ${ }^{3}$ Department of Software Engineering, Faculty of Engineering, Koya University, Koya KOY45, \\ Kurdistan Region - F.R. Iraq \\ ${ }^{4}$ Imec-Vision Lab, Department of Physics, University of Antwerp, \\ Antwerp, Belgium
}

\begin{abstract}
In this paper, the implementation of artificial neural networks (multilayer perceptron [MLP] and radial base functions [RBF]) and the upgraded Markov chain model have been studied and performed to identify the human behavior patterns during rock, paper, and scissors game. The main motivation of this research is the design and construction of an intelligent robot with the ability to defeat a human opponent. MATLAB software has been used to implement intelligent algorithms. After implementing the algorithms, their effectiveness in detecting human behavior pattern has been investigated. To ensure the ideal performance of the implemented model, each player played with the desired algorithms in three different stages. The results showed that the percentage of winning computer with MLP and RBF neural networks and upgraded Markov model, on average in men and women is $59 \%, 76.66 \%$, and $\mathbf{7 5 \%}$, respectively. Obtained results clearly indicate a very good performance of the RBF neural network and the upgraded Markov model in the mental modeling of the human opponent in the game of rock, paper, and scissors. In the end, the designed game has been employed in both hardware and software which include the Zana intelligent robot and a digital version with a graphical user interface design on the stand. To the best knowledge of the authors, the precision of novel presented method for determining human behavior patterns was the highest precision among all of the previous studies.
\end{abstract}

Index Terms-Multilayer perceptron, Radial basis functions, upgraded Markov model, Rock, paper, Scissors game.

ARO-The Scientific Journal of Koya University Vol. IX, No.1 (2021), Article ID: ARO.10757, 10 pages DOI: $10.14500 /$ aro. 10757

Received: 27 November 2020; Accepted: 21 February 2021

Regular research paper: Published: 08 March 2021

Corresponding author's e-mail: hosseinroshani@kut.ac.ir Copyright (C) 2021 Maryam Ghasemi, Abdolreza Roshani, Peshawa J. Muhammad Ali, Farhad F. Nia, Ehsan Nazemi and Gholam H. Roshani. This is an open-access article distributed under the Creative Commons Attribution License.

\section{INTRODUCTION}

Playing is a purposeful physical or mental activity that is performed individually or in groups with the aim of entertainment and leisure. Each game contains its own set of players, moves, or strategies as well as the principles and rules. Winning in every game is not only a function of luck but also each player during the game can move toward the victory by applying the rules of the game. Games often have well-known forms and have social, climatic, and cultural contexts (Ahmadvand, 1993). Among all games, the game of rock, paper, and scissors has a very simple environment and is considered a traditional and popular game that almost people of all ages can enjoy playing the game.

Rock, paper, and scissors are a hand game which is usually played among two players (Ali et al., 2000). This game describes a cycle between three competing species in a network (Hu et al., 2019). Each player puts his hand in one of the three allowed positions. The rock is shown with a closed fist. The scissors with closed hands whereas middle and index fingers are stretched and the paper is shown with the open palm and fingers glued together. According to Fig. 1, the general rule of the game is such a way that the rock beats the scissors, the scissors beats the paper, and the paper beats the rock.

In general, humans do not perform very well in random activities. Investigations of the behavior of the human players in this game conducted by scientists revealed that most of them have a predictable behavior pattern. Since the adaptability of the rock, paper, and scissors' game leads to a change in the player's strategy over the course of time, this game can be considered a good sample for testing the theory of behavior of human short-term memory (Ali et al., 2000). In game theory, we observe concepts that can model 


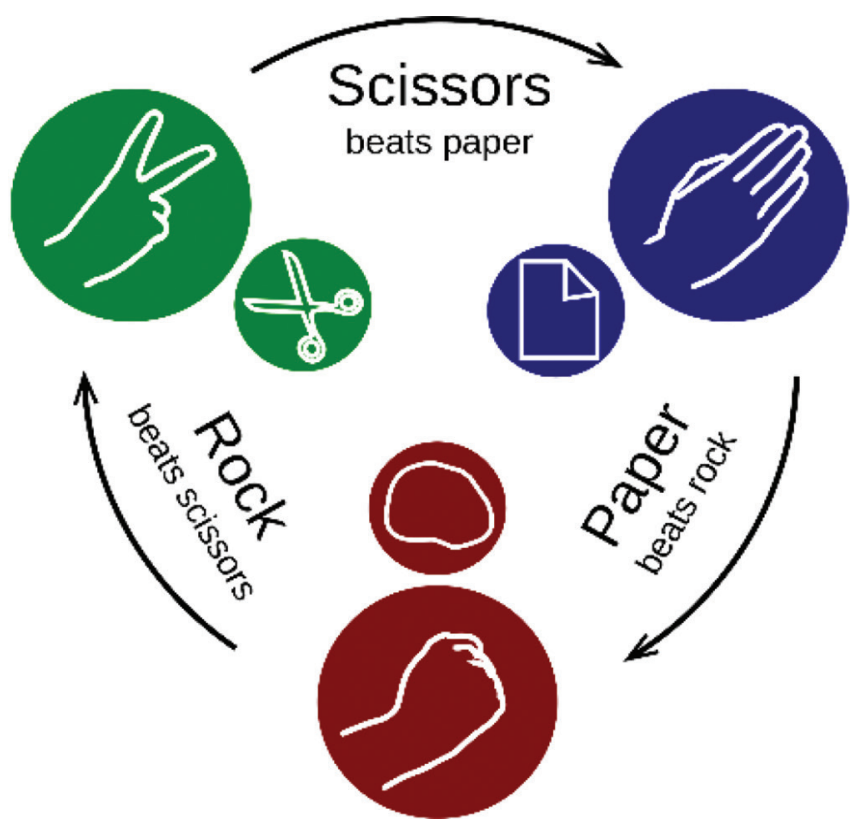

Fig. 1. The rules of rock-paper-scissors game (https://en.wikipedia.org).

abstract evolutionary systems very well. Among them, we can refer to the intelligent player of rock-paper-scissors who has the ability to recognize the human behavior pattern and defeat him. The development of smart players requires that their behavior to be consistent with the behavior of other players. Since creating such a player increases the excitement and difficulty of this game, special attention is paid to this problem in the gaming industry (de Souza et al., 2013). In this paper, a novel method to determine human behavior patterns during rock, paper, and scissors game was presented with high precision. To the best knowledge of the authors, the precision of novel presented method is the highest precision among all of the previous studies.

\section{LiterATURE REVIEW}

Game and entertainment, especially group games, have played an important role in the history of humankind. However, choosing the initial player at the beginning of group games has always been the main concern of the participants of those games. In the $18^{\text {th }}$ century, a game called Jon_Ken_Pon was invented in Japan in an attempt to solve this problem, which is currently known as Rock-PaperScissors (Hasuda et al., 2007). Until recently, many studies have been accomplished in this field, which we will review in the following:

Ali et al. (2000) proposed a way to create an intelligent player in the game of rock-paper-scissors using genetic algorithm. In this method, a genetic string is encoded to train the intelligent player. Decent disciplines were produced in later generations, and eventually an evolved system created in which, instead of making unbiased decisions, it used the player's behavior in previous games to make concrete decisions in the current game. Another proper way to create an intelligent player of rock-paper-scissors was proposed by de Souza et al. (2013). To achieve this goal, they used the WIZARD weightless neural network. The WIZARD device is a general system made of small units of RAM that can detect and classify different patterns. The learning operation is based on reading and writing in different locations of the memory, which makes this model effective for creating intelligent players. In this model, three training algorithms are proposed to classify input patterns over the time. It also includes a new function for encoding input data and a method to deal with incomplete information in input arrays. Cenggoro et al. (2014) proposed a technique to determine the player's future behavior in the game of rock-paper-scissors using the feed forward neural network. In a study by Salvetti et al. (2007), a new method based on entropy and LLE ${ }^{1}$ indicators was proposed to predict the appropriate moment to use rock, paper, or scissors during the game. The right moment is when the opponent's future behavior is more predictable. The intelligent player then makes a choice to defeat the opposing player. Ghasemi et al. (2020) presented a suitable strategy for detecting human behavioral patterns in the game of rockpaper-scissors using the multilayer perceptron neural network (MLP). In the first step, the neural network learns the pattern of human behavior and in the second step; it is ready to play a real game against her or him. The results of the study for this network on 40 people showed the good performance of the MLP network in detecting human behavior patterns. Matsumoto et al. (2012) developed a program for automatic judgment in the game of rock-paper-scissors. In their work, first, using the C-Means classification method, the numbers, and the locations of the hands in the images of rock-paperscissors are estimated, and then according to the difference between the compression of the categories, the winning, and losing judgments are made. Studies have also been carried out to diagnose hand postures (rock-paper-scissors). Chen et al. (2010) used the image processing method to investigate this. Initially, the hand image is extracted from consecutive images and then it is used to produce a binary image and filter out the interference, overall threshold, and skin color. Their main focus in this article was to identify the scissors because it involves the state of consecutive errors, whereas identifying rock and paper is rather easy. The number of zero-fingers represents rock and the number of five-fingers represents paper. If the number of fingers is 2 , hence there are eight different shapes, of which only 1 is correct. To avoid the error, the distance between two fingers is used, which is the same criterion for determining the position of the scissors in some cases and to solve this problem they used the methods of division, histogram, and angle criterion. Gang et al. (2017) suggested a method to classify electromyographic (EMG) signals according to hand postures (rock-paper-scissors) by using MLP. In this method, EMGs are applied to the Hezajac-levine bilinear activation model, and then the output of the model is used as MLP inputs. Besides, cross validation method was also used to evaluate the performance of MLP classification. Hasuda et al. (2007) designed a robot that plays rock-paper-scissors in front of a human. The designed

1 Local Lyapunov Exponent 
robot includes a camera, an image processor, an evaluation system, an audio system, and also a body. In fact, the image processing system was developed to detect the shape of the human hand, and the evaluation system estimates the output of the game by comparing the shape of the player's hand with the robot. To communicate with humans effectively, this robot is able to express emotions through the sound, body gesture, and facial expressions, and also has the ability to talk to the player. In another study by Ahmadi et al. (2019), an intelligent robot named Rasa was developed to play stonepaper-scissors against humans. In the first step, the designed robot detects the movement of the player's hand using a Leap Motion sensor as well as an MLP network. In the second step, using the Markov chain model, he predicts the player's future movement. Another intelligent robot was constructed by Pozzato et al. (2013). In this robot, the Gaussian mixture model algorithm is used to predict the future movement of the player in the game of rock-paper-scissors.

In this paper, artificial neural networks (ANNs) (MLP and radial base functions $[\mathrm{RBF}]$ ) and upgraded Markov chain model were used to build up an intelligent rock-paper-scissors player. In these algorithms, artificial intelligence learns the pattern of human behavior. Afterward, it will be able to predict the future movement of the human opponent and to defeat him by providing an appropriate answer. To ensure the ideal performance of the modeling, the effectiveness of intelligent algorithms in detecting the behavioral pattern of players was evaluated and the percentage of winner computer was calculated. In addition, another program was written to calculate the percentage of a winner computer without an intelligent algorithm for playing rock-paper-scissors against humans. In this program, all computer selections are random. Subsequently, this strategy was implemented in two physical ways. In the prototype, a robotic hand was used that performs one of the movements of rock, paper or scissors for each step of the game with the decision-making power of artificial intelligence written on the Zana robot processor. In the second phase, to make the graphical appearance of the game suitable and attractive, the possibility to play against a human opponent was added to the design of robot using the MATLAB graphical user interface (GUI) in a computer system and embedding it into a designed stand.

\section{Mental Modeling}

\section{A. ANN S}

ANNs have become the most widely used method for predicting various systems. With great negligence, these networks can be called electronic models of the neural structure of the human brain (Menhaj, 2008). According to this assumption, information processing takes place in simple elements, which are referred to as neurons. Electrical signals are transmitted between neurons and on junctions. Each connection has an associated weight that multiplies the transmitted signals in the neural network. This weight can be used to amplify or weaken the signal. Each neuron applies an activator function to its input to determine the output signal
(Fausett, 2006). In fact, the purpose of creating a softwarebased neural network is to create a mechanism for solving engineering problems, inspired by the behavioral pattern of biological networks rather than simulating the human brain (Menhaj, 2008). Recently, different kinds of ANNs have important role in solving different complex problems of engineering (Roshani, et al., 2014, Nazemi, et al., 2015, Roshani, et al., 2016, Roshani, et al., 2017a, Roshani, et al., 2017b, Jamshidi, et al., 2020, Roshani, et al., 2020, Roshani, et al., 2021a, Roshani, et al., 2021b, Roshani, et al., 2021c).

\section{B. MLP Network}

The MLP network is a class of ANNs. An MLP consists of at least three layers: An input layer, a hidden layer, and an output layer. The neurons in each layer connect to all the neurons in the next layer (Roshani et al., 2018). Error propagation algorithm is the most widely used method for training multilayer networks (Dehlaghi et al., 2015). The structure of the MLP network designed to detect human behavioral patterns in the game of Rock-Paper-Scissors is illustrated in Fig. 2. This structure was optimized using presented algorithm in our previous study (Roshani et al., 2018).

According to the designed MLP network structure shown in Fig. 2, the input layer has four neurons, which are the computer and player selections in two consecutive rounds. The target output of this network is player selection in the round right after two consecutive rounds. Table I shows the characteristics of the MLP network designed for detecting human behavior patterns in the game of rock-paper-scissors.

\section{Radial Basis Function Network}

Radial basis functions are another type of feed forward neural networks. The process of such networks depends on the radial distance from specific points. There are three types of layers in RBF networks: Input layer, hidden layer, and output layer. In the hidden layer, each node applies a radial function that has its own center and radius to the inputs. The output of this network is a linear combination of radial basis functions for input parameters and neurons. The structure of the RBF network designed to detect the pattern of human behavior in the game of rock-paper-scissors is depicted in Fig. 3. Table II shows the characteristics of the RBF network designed for detecting the pattern of human behavior in the game of rock-paper-scissors.

\section{Design Algorithm of Rock-Paper-Scissors Game with ANNs}

The algorithm for designing rock-paper-scissors consists of two stages. In the first stage, to train the neural network, 40 rounds of game are played between the computer and the player. In the second stage, the computer will be able to predict ten future moves of the human opponent. Flowchart of the game design of rock-paper-scissors with neural network is plotted in Fig. 4.

\section{Step 1: Neural network training}

In the game of rock-paper-scissors, the strategy of the opponents' game changes over time and also in each game. 


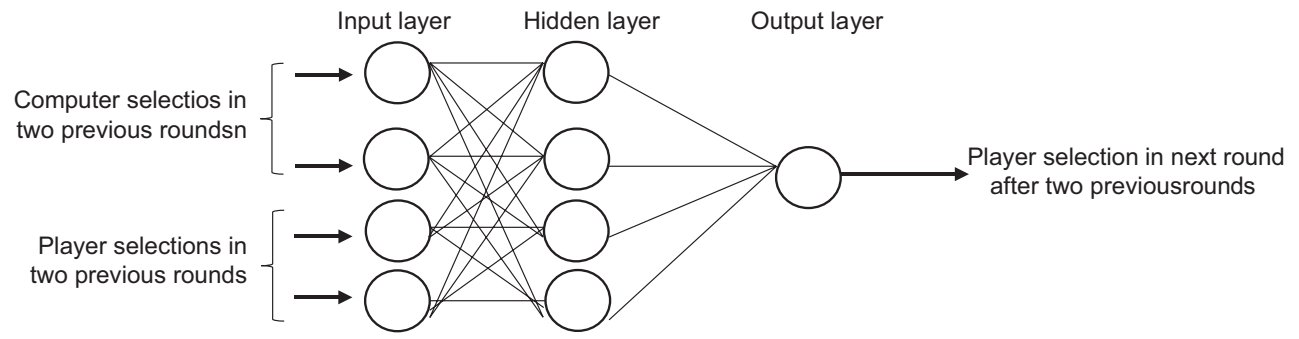

Fig. 2. Multilayer perceptron network structure designed for detecting human behavioral pattern.

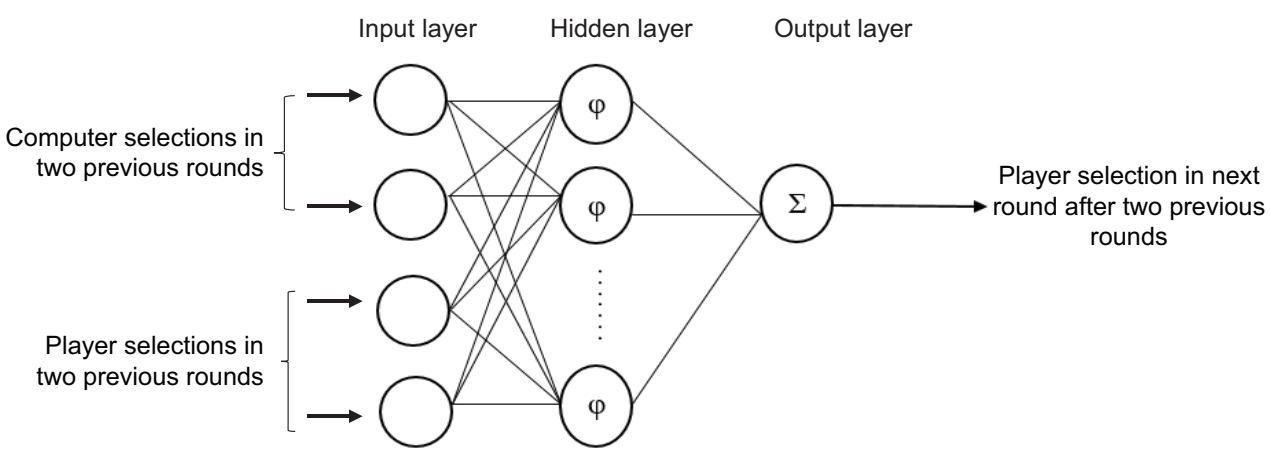

Fig. 3. Radial basis functions network structure designed for detecting human behavioral pattern.

TABLE I

MLP NETWORK SPECIFICATION WHICH WAS DESIGNED TO DETECT HUMAN BEHAVIORAL PATTERN

\begin{tabular}{lc}
\hline \hline Applied network & MLP \\
\hline The number of neurons in the input layer & 4 \\
The number of neurons in the hidden layer & 4 \\
The number of neurons in the output layer & 1 \\
The number of epochs & 70 \\
Activation function & Tansig \\
\hline \hline
\end{tabular}

TABLE II

RADIAL BASIS FUNCTIONS NETWORK SPECIFICATION WHICH WAS DESIGNED TO DETECT HUMAN BEHAVIORAL PATTERN

\begin{tabular}{lc}
\hline \hline Applied network & Radial basis functions \\
\hline The number of neurons in the input layer & 4 \\
The number of maxnurons & 18 \\
The number of neurons in the output layer & 1 \\
Spread & 3 \\
Goal & 0 \\
\hline \hline
\end{tabular}

Therefore, it is necessary to adjust the network's knowledge according to the way that each player plays. At this stage, at the same time as the computer and the player play, the input data matrix is formed for training and testing the neural network. In this regard, first 40 rounds of game are played between the computer and the player. The purpose of this stage is to enable the neural network to learn the general pattern player's behavior. All computer selections are random. Each of the hand modes, rock, paper, and scissors is defined by the numbers 2,1 , and 3, respectively. For example, supposing that the computer and player selections are as follows then the steps of forming the input data matrix and the target output are shown in Fig. 5.

As shown in Fig. 5, first, the computer and player selections in 40 rounds are placed in a matrix with 40 rows and two columns. The first column is the computer selection and the second column is the player selection. In the next step, the previous matrix is transformed into a matrix with 39 rows and four columns so that the first and second selections of the computer as well as the player are placed in two consecutive rounds on one row, and then the second and third selections of the computer and the player are placed on the next row. This process continues until the fortieth round. In the next step, the matrix of the previous step becomes a matrix with 38 rows and five columns. The fifth column is the target output. This column is the selection of the player in the round right after two consecutive rounds. In the last step, the matrix columns are separated. The first till the fourth columns are considered as input data and the fifth column is considered as target output. To develop the ANN model, the number of training, test, and validation data is equal to (70\%) $26,(15 \%) 6$, and (15\%) 6, respectively. The low error of predicted data in testing set shows that the over fitting problem has not been occurred and the presented model is accurate and precise.

\section{Step 2: The real game}

The trained neural network has already learned the general pattern of player's behavior base on 40 rounds of the game and now is ready for the real game against her/him. Ten rounds, that is, 41-50, are considered for this stage. In the real game, the neural network uses the player and computer selections in the previous two consecutive rounds as input data to predict the player's future move in the round right after these two rounds, then defeats the opposing player with choosing the right selection. For example, in the $41^{\text {st }}$ round, the player and computer selections in the $39^{\text {th }}$ and $40^{\text {th }}$ rounds, that is, two consecutive rounds before, will be given to the neural network to predict the player's behavior. This 


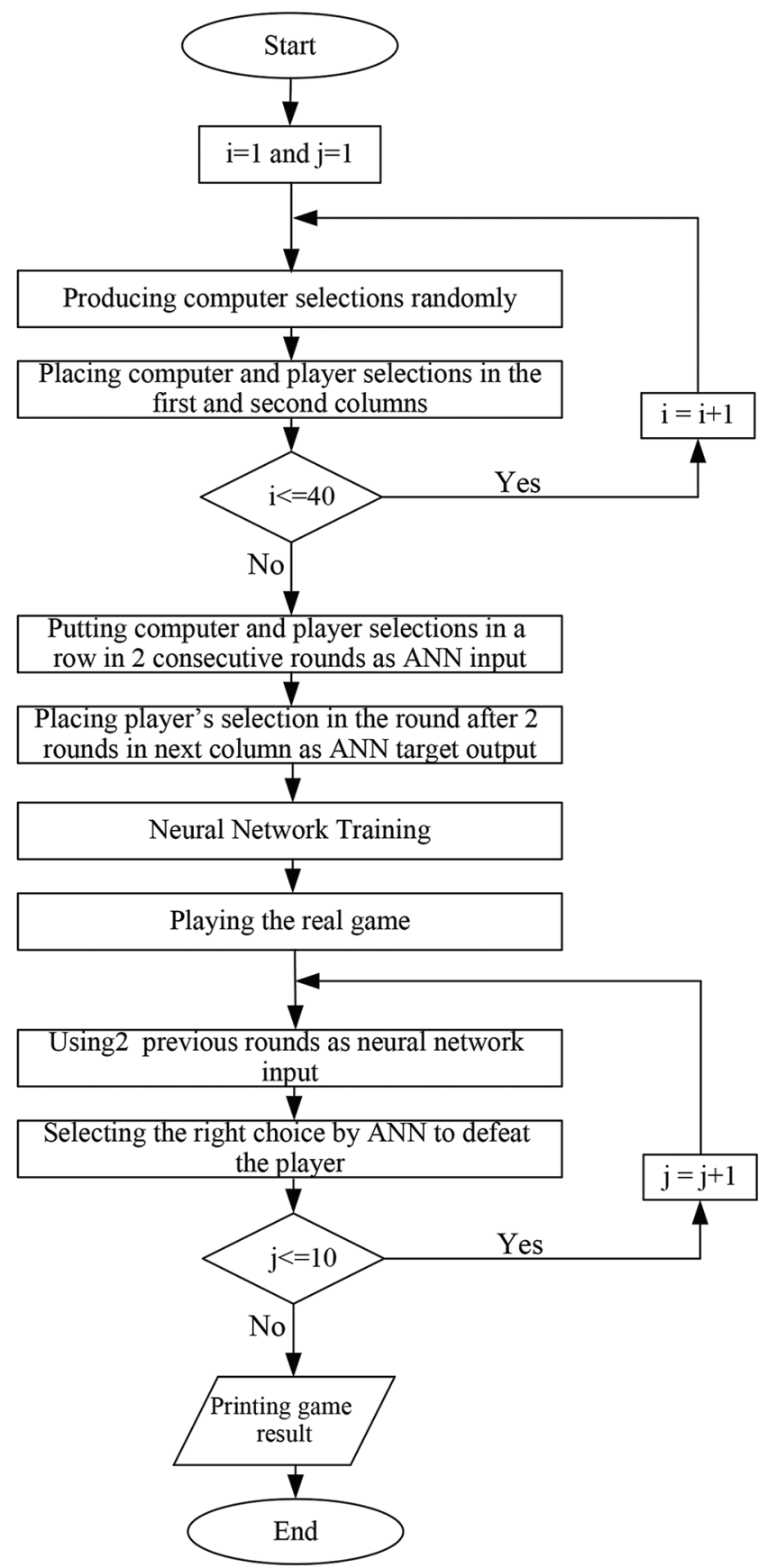

Fig. 4. Flowchart of rock-paper-scissors game designed with the neural network.

process will continue until the last round. The effectiveness of the neural network in detecting human behavior patterns and defeating players will be determined at this very stage (Real game). Finally, the winning percentage of the computer is calculated.

Then, to examine the computer winning percentage without a neural network, another program was written to play rockpaper-scissors against humans. All computer selections in this program are random. 50 rounds of game are played between the computer and the player. To create the same conditions as the neural network program, the last ten rounds, that is, 41-50, will be considered as the real game.

\section{E. Upgraded Markov Chain Model}

The random process whose future probabilities are calculated based on the recent values is called the Markov process (He, et al., 2019). The Markov chain is a statistical tool used to determine the probability of transitions between several states, which is used to model and predict the effect of future changes. If we put these probabilities inside a matrix, we get the Transition Probability Matrix (De Caro et al., 2019).

Humans always apply mental and psychological factors in their decisions. This is also the case in the game of rockpaper-scissors. In this way, the player's movement in the next game is affected by the result of the previous game. A special feature of this intelligent algorithm is to enter the results of the game in the Markov matrix. The designed upgraded Markov model to predict the future movement of the player in the game of rock-paper-scissors is a $9 \times 3$ matrix. According to Fig. 6, this matrix contains the player's movements (rock-paper-scissors) that have caused him to win, lose, or draw with the computer.

\section{Forming a Markov matrix and predicting the player's future movements}

First of all, all matrix values are zero. Then, according to the number of rounds of the game, the player's movements and the result of each round, the value of the elements increases as a unit. The player's selections are placed in the matrix in two consecutive rounds according to the result of the previous two rounds. For example, if a player's selections in two consecutive rounds are paper and rock, respectively, and the result of the first round (the previous two rounds) is a player's loss, one unit is added to element of the fifth row and first column of the matrix, because the player has moved from paper (that caused him to lose) to rock. This process continues until the last round, and the Markov matrix is formed at the same time as the computer and the player keep playing.

In the first and second rounds, the computer selections are random. From the third round onwards, the computer makes its selection according to the player's choice in the previous round and the result of this round. For example, if the player selected scissors in the previous round and the result of this round is a computer's win, a comparison is made between the third row elements. Whichever is larger, the computer tries to defeat the player by performing the opposite move. For example, if the value of the element of the third row and the first column is more than the other two elements, it means that the player usually moves from the scissors (which caused him to win) to the rock. In the next round, the computer chooses the paper to defeat him/ her. This forecasting process will continue until the last round.

\section{Physical Implementation}

This game is implemented in two physical forms; the prototype has been designed and built robotically as the first form. Zana robot consists of two parts: Hardware 


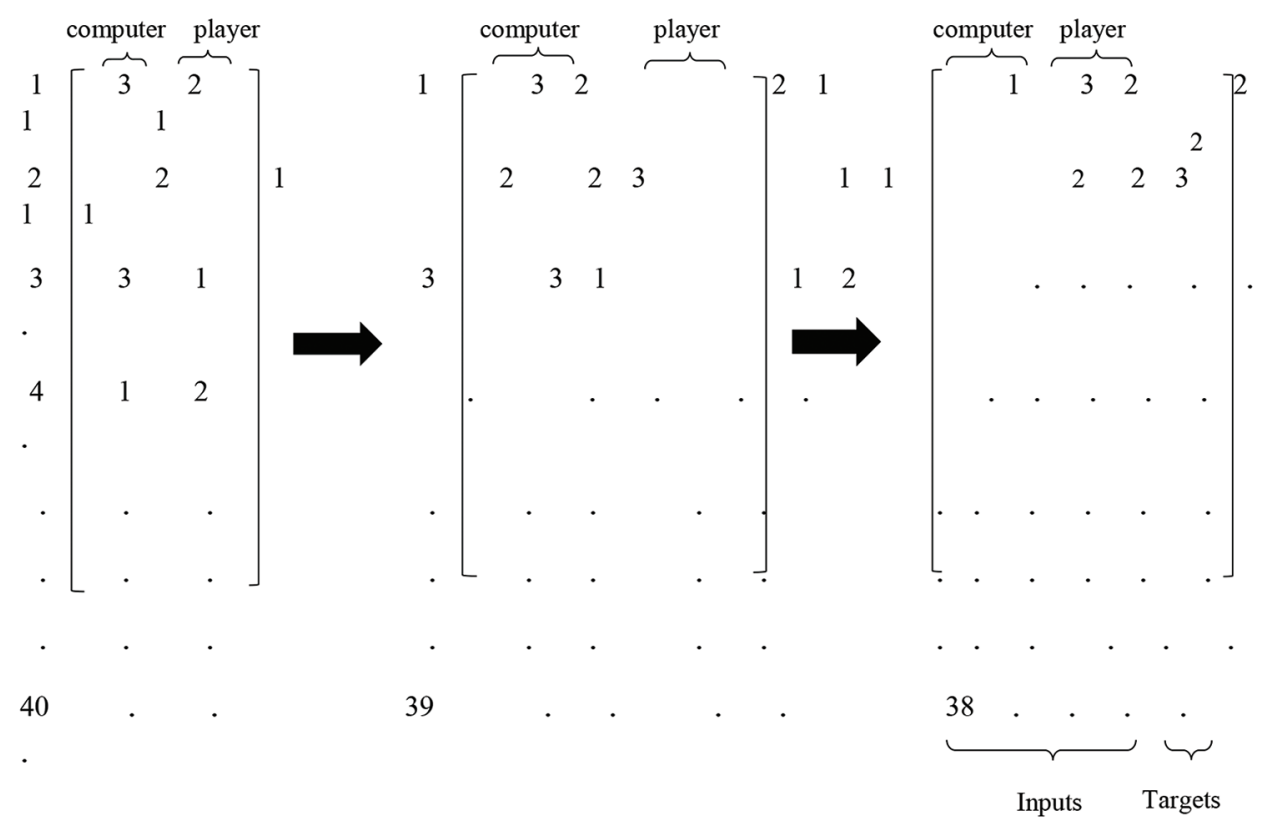

Fig. 5. The steps of forming the input data and target output matrix

\begin{tabular}{|c|c|c|c|c|c|}
\hline & & & Rock & Paper & Scissor \\
\hline \multirow{3}{*}{ Player win } & Rock & 1 & P11 & P12 & P13 \\
\hline & Paper & 2 & P21 & P22 & $\mathrm{P} 23$ \\
\hline & Scissor & 3 & P31 & P32 & P33 \\
\hline \multirow{3}{*}{ Player loss } & Rock & 4 & P41 & P42 & P43 \\
\hline & Paper & 5 & P51 & P52 & P53 \\
\hline & Scissor & 6 & P61 & P62 & P63 \\
\hline \multirow{3}{*}{ Tie } & Rock & 7 & P71 & P72 & P73 \\
\hline & Paper & 8 & P81 & P82 & P83 \\
\hline & Scissor & 9 & P91 & P92 & P93 \\
\hline
\end{tabular}

Fig. 6. The transition probability matrix of Markov upgraded

and software. The hardware part of this robot performs the movements of rock-paper-scissors through the motors installed in its structure. Zana robot's control unit has a processor (microcontroller) to control finger movement. There are also three separate keys for the user to select from one of the modes of rock-paper-scissors. Using the AVR microcontroller and its algorithm written in $\mathrm{C}$, the robot is equipped with artificial intelligence, according to which the Zana robot decides at any round of the game to choose one of the rock, paper, or scissors modes. A character LCD has been also used to display the game result.

In the second form, to have a graphically appropriate and attractive appearance for the game, a stand has been designed using the GUI and coding in the App designer environment in a computer system, and then it was embedded in the designed stand such that it can be played against a human opponent. The stand uses an LCD to display the game environment and the results. A speaker is also used to produce audio effects to make the device more attractive with a nice looking. Images of Zana intelligent robot, graphic environment, and the designed stand for playing rock-paper-scissors game are shown in Figs. 7 and 8.

\section{RESULTS}

\section{A. Evaluation of the Effectiveness of ANNs in Detecting Human behavior Pattern}

ANNs (MLP and RBF) designed for detecting human behavior in a game of rock-paper-scissors were tested among 20 people (ten women and ten men). Players are of from different ages and levels of education. Each player played with the desired networks in three stages. The effectiveness

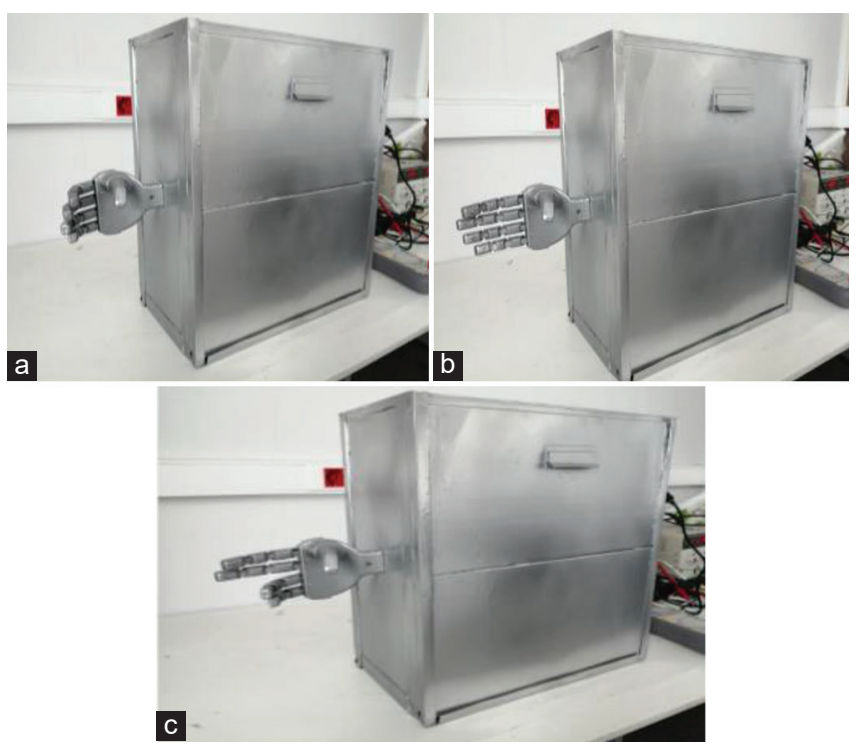

Fig. 7. Robot gestures: (a) Rock, (b) Paper, (c) Scissors. 
of ANNs in defeating players and the percentage of winning computer were calculated. According to the results presented in Tables III and IV, the percentage of winning computer with MLP neural network designed in 30 games played among men is equal to $55 \%$ and with the same number of games in women is equal to $63.33 \%$ and the percentage of winning computer with RBF neural network is $75 \%$ in men and $78.33 \%$ in women. Nevertheless, the percentage

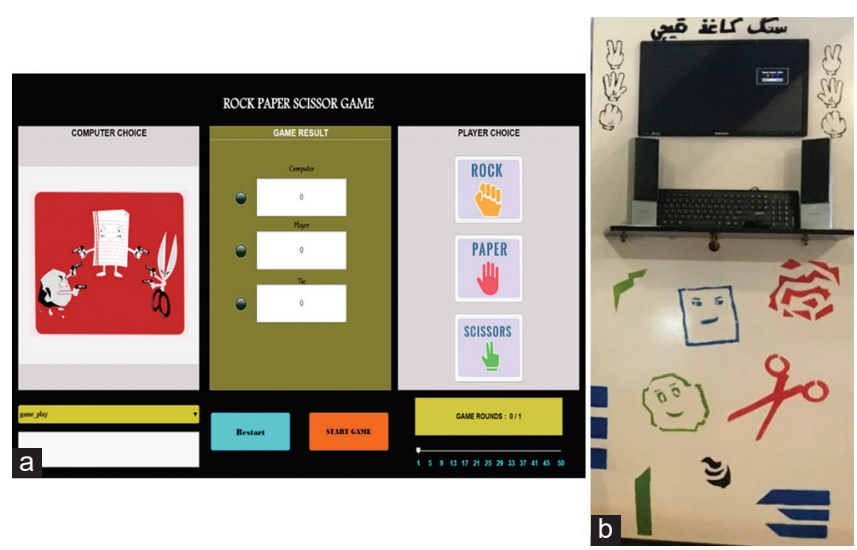

Fig. 8. (a) Graphic environment, (b) designed stand for playing rockpaper-scissors game. of winning computer without neural network among men and women's players and with the same number of games is equal to $50 \%$ and $45 \%$, respectively. The results show the good performance of the neural network in detecting human behavior in the game of rock-paper-scissors. It is evident that the RBF network is more effective in defeating players than the MLP network, and also the percentage of winning computer in women's players is higher than men's players. Table V shows the number of wins, losses, and ties of the computer in 30 games among men and women with the mentioned neural networks and without the neural network. According to the results presented in this table, RBF neural network has been able to win 21 games out of 30 games played with men and 22 games out of 30 games played with women. These results show the very good performance of this network in modeling the human mind in the game of rock-paper-scissors.

\section{B. Evaluation of the Effectiveness of the Upgraded Markov Model in Detecting Human behavior Pattern}

The upgraded Markov model designed for detecting human behavior patterns in the game of rock-paper-scissors was tested among 20 people (ten women and ten men).

TABLE III

GAME RESULTS AND COMPUTER WINNING PERCENTAGE IN MEN WITH AND WITHOUT NEURAL NETWORKS (C, P, AND T IS COMPUTER WINS, PLAYER WINS AND TIE, RESPECTIVELY)

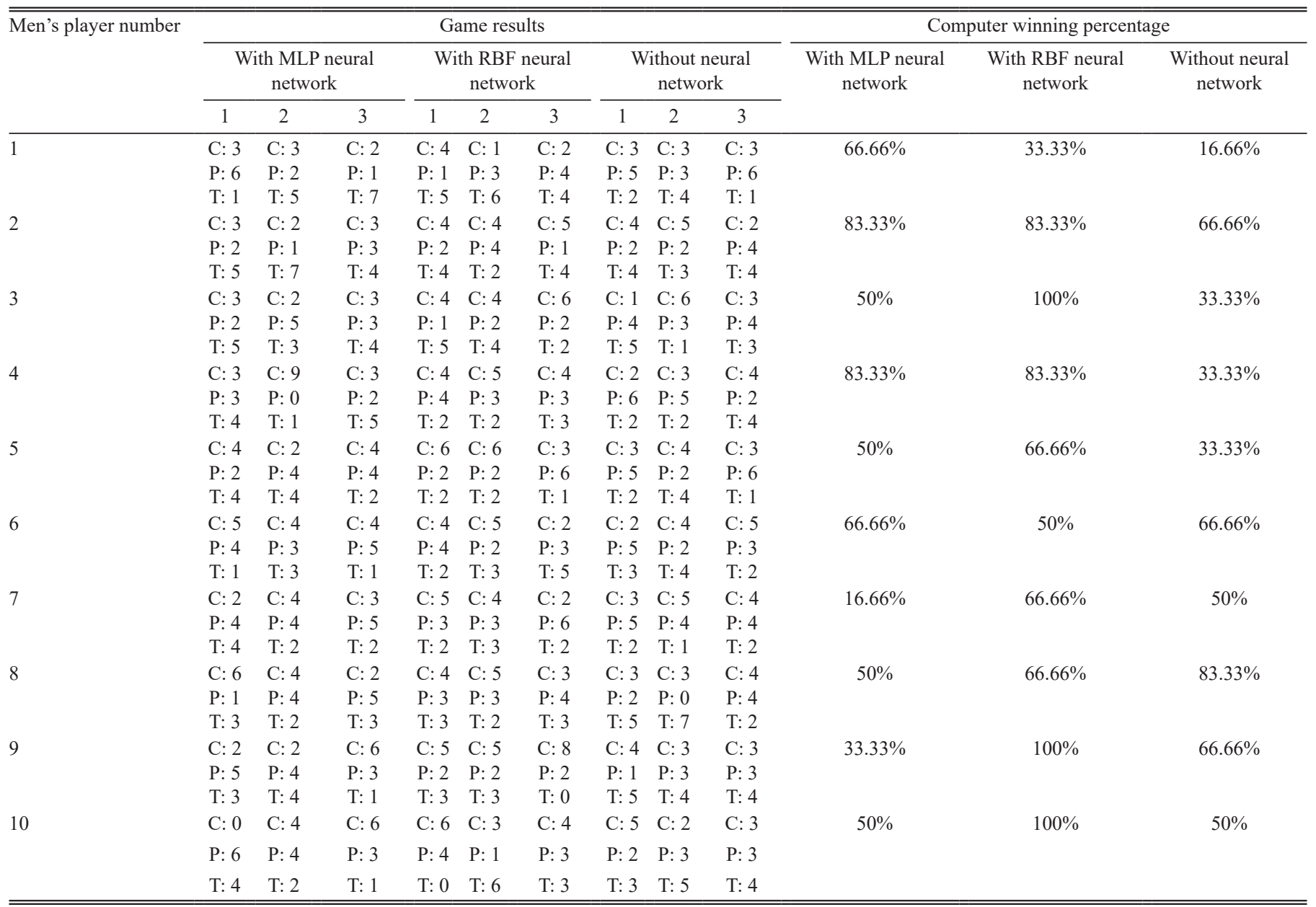


TABLE IV

GAME RESULTS AND COMPUTER WINNING PERCENTAGE IN WOMEN WITH AND WITHOUT NEURAL NETWORKS (C, P, AND T IS COMPUTER WINS, PLAYER WINS AND TIE, RESPECTIVELY)

\begin{tabular}{|c|c|c|c|c|c|c|c|c|c|c|c|c|}
\hline \multirow[t]{3}{*}{ Women's player number } & \multicolumn{9}{|c|}{ Game results } & \multicolumn{3}{|c|}{ Computer winning percentage } \\
\hline & \multicolumn{3}{|c|}{$\begin{array}{l}\text { With MLP neural } \\
\text { network }\end{array}$} & \multicolumn{3}{|c|}{$\begin{array}{l}\text { With RBF neural } \\
\text { network }\end{array}$} & \multicolumn{3}{|c|}{$\begin{array}{c}\text { Without neural } \\
\text { network }\end{array}$} & \multirow[t]{2}{*}{$\begin{array}{c}\text { With MLP neural } \\
\text { network }\end{array}$} & \multirow[t]{2}{*}{$\begin{array}{c}\text { With RBF neural } \\
\text { network }\end{array}$} & \multirow[t]{2}{*}{$\begin{array}{c}\text { Without neural } \\
\text { network }\end{array}$} \\
\hline & 1 & 2 & 3 & 1 & 2 & 3 & 1 & 2 & 3 & & & \\
\hline \multirow[t]{3}{*}{1} & C: 4 & $\mathrm{C}: 1$ & C: 5 & C: 7 & C: 5 & C: 4 & C: 2 & C: 6 & C: 3 & $66.66 \%$ & $100 \%$ & $33.33 \%$ \\
\hline & P: 3 & P: 5 & P: 2 & P: 1 & P: 1 & P: 1 & P: 6 & P: 3 & P: 4 & & & \\
\hline & $\mathrm{T}: 3$ & $\mathrm{~T}: 4$ & $\mathrm{~T}: 3$ & $\mathrm{~T}: 2$ & $\mathrm{~T}: 4$ & $\mathrm{~T}: 5$ & $\mathrm{~T}: 2$ & $\mathrm{~T}: 1$ & $\mathrm{~T}: 3$ & & & \\
\hline 2 & $\mathrm{C}: 2$ & $\mathrm{C}: 3$ & C: 6 & $\mathrm{C}: 4$ & C: 4 & C: 3 & $\mathrm{C}: 3$ & $\mathrm{C}: 3$ & $C: 3$ & $50 \%$ & $83.33 \%$ & $0 \%$ \\
\hline \multirow[t]{3}{*}{3} & C: 6 & $\mathrm{C}: 1$ & C: 4 & C: 0 & C: 7 & C: 9 & C: 4 & $\mathrm{C}: 3$ & C: 7 & $66.66 \%$ & $66.66 \%$ & $50 \%$ \\
\hline & P: 3 & P: 4 & P: 2 & P: 6 & P: 2 & P: 0 & P: 4 & P: 6 & P: 3 & & & \\
\hline & $\mathrm{T}: 1$ & $\mathrm{~T}: 5$ & $\mathrm{~T}: 4$ & $\mathrm{~T}: 4$ & $\mathrm{~T}: 1$ & $\mathrm{~T}: 1$ & $\mathrm{~T}: 2$ & $\mathrm{~T}: 1$ & $\mathrm{~T}: 0$ & & & \\
\hline \multirow[t]{3}{*}{4} & C: 3 & C: 1 & C: 2 & C: 4 & C: 4 & C: 3 & C: 3 & $\mathrm{C}: 1$ & C: 5 & $33.33 \%$ & $66.66 \%$ & $50 \%$ \\
\hline & P: 1 & P: 6 & P: 4 & P: 2 & P: 2 & P: 4 & $P: 3$ & $P: 3$ & P: 1 & & & \\
\hline & T: 6 & $\mathrm{~T}: 3$ & $\mathrm{~T}: 4$ & $\mathrm{~T}: 4$ & $\mathrm{~T}: 4$ & $\mathrm{~T}: 3$ & $\mathrm{~T}: 4$ & $\mathrm{~T}: 6$ & $\mathrm{~T}: 4$ & & & \\
\hline & $\mathrm{P}: 2$ & P: 6 & P: 2 & P: 6 & P: 1 & $P: 3$ & $P: 3$ & P: 2 & P: 5 & & & \\
\hline & $\mathrm{T}: 3$ & $\mathrm{~T}: 1$ & $\mathrm{~T}: 4$ & $\mathrm{~T}: 1$ & $\mathrm{~T}: 6$ & $\mathrm{~T}: 5$ & $\mathrm{~T}: 4$ & $\mathrm{~T}: 2$ & $\mathrm{~T}: 4$ & & & \\
\hline \multirow[t]{3}{*}{7} & C: 4 & C: 2 & C: 6 & C: 3 & C: 6 & $\mathrm{C}: 2$ & C: 2 & C: 3 & C: 5 & $100 \%$ & $100 \%$ & $66.66 \%$ \\
\hline & P: 3 & P: 1 & P: 3 & P: 2 & P: 1 & P: 1 & P: 5 & P: 2 & P: 2 & & & \\
\hline & $\mathrm{T}: 3$ & $\mathrm{~T}: 7$ & $\mathrm{~T}: 1$ & $\mathrm{~T}: 5$ & $\mathrm{~T}: 3$ & $\mathrm{~T}: 7$ & $\mathrm{~T}: 2$ & $\mathrm{~T}: 5$ & $\mathrm{~T}: 3$ & & & \\
\hline \multirow[t]{3}{*}{8} & $C: 3$ & C: 6 & C: 6 & $\mathrm{C}: 2$ & C: 4 & C: 5 & C: 4 & $\mathrm{C}: 2$ & C: 4 & $100 \%$ & $66.66 \%$ & $66.66 \%$ \\
\hline & P: 1 & P: 1 & P: 1 & P: 3 & P: 2 & P: 2 & P: 3 & P: 6 & P: 2 & & & \\
\hline & $\mathrm{T}: 6$ & $\mathrm{~T}: 3$ & $\mathrm{~T}: 3$ & $\mathrm{~T}: 5$ & $\mathrm{~T}: 4$ & $\mathrm{~T}: 3$ & $\mathrm{~T}: 3$ & $\mathrm{~T}: 2$ & $\mathrm{~T}: 4$ & & & \\
\hline \multirow[t]{3}{*}{9} & C: 4 & C: 4 & C: 3 & C: 5 & C: 7 & C: 5 & C: 4 & C: 4 & $\mathrm{C}: 1$ & $83.33 \%$ & $100 \%$ & $50 \%$ \\
\hline & P: 3 & P: 1 & P: 3 & P: 1 & P: 3 & P: 2 & P: 1 & P: 4 & P: 4 & & & \\
\hline & $\mathrm{T}: 3$ & $\mathrm{~T}: 5$ & $\mathrm{~T}: 4$ & $\mathrm{~T}: 4$ & $\mathrm{~T}: 0$ & $\mathrm{~T}: 3$ & $\mathrm{~T}: 5$ & $\mathrm{~T}: 2$ & $\mathrm{~T}: 5$ & & & \\
\hline 10 & C: 5 & C: 4 & C: 3 & C: 4 & C: 6 & C: 8 & C: 4 & C: 3 & $C: 3$ & $33.33 \%$ & $83.33 \%$ & $16.66 \%$ \\
\hline
\end{tabular}

TABLE V

NUMBER OF COMPUTER WINS, LOSSES AND TIES IN 30 GAMES AMONG MEN AND WOMEN WITH AND WITHOUT NEURAL NETWORKS

\begin{tabular}{|c|c|c|c|c|c|c|c|c|c|}
\hline \multirow[t]{3}{*}{$\overline{\text { Sexuality }}$} & \multicolumn{9}{|c|}{30 games played } \\
\hline & \multicolumn{3}{|c|}{ With MLP neural network } & \multicolumn{3}{|c|}{ With RBF neural network } & \multicolumn{3}{|c|}{ Without neural network } \\
\hline & Computer wins & Computer losses & Ties & Computer wins & Computer losses & Ties & Computer wins & Computer losses & Ties \\
\hline Women & 18 games & 10 games & 2 games & 22 games & 5 games & 3 games & 11 games & 14 games & 5 games \\
\hline
\end{tabular}

To evaluate the performance of the modeling, each of the players played in three stages with 15 and 20 rounds with the desired intelligent algorithm. The effectiveness of the upgraded Markov model in defeating players and the percentage of winning computer were calculated. According to the results presented in Tables VI and VII, the percentage of winning computer with the 15 rounds in 30 games played with men is equal to $68.33 \%$ and with the same number of games with women is equal to $70 \%$, whereas the percentage of winning computer with the 20 rounds with men is equal to $73.33 \%$ and with women is equal to $76.66 \%$. Table VIII shows the number of wins, losses, and ties of the computer in 30 games among men and women. The results show the very good performance of the improved Markov model in detecting human behavior in the game of rock-paper-scissors.

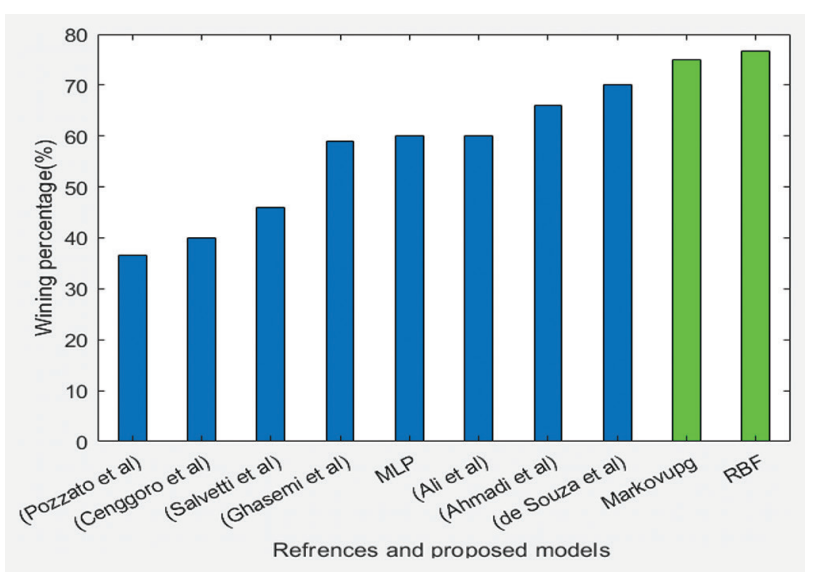

Fig. 9. Winning percentage of the proposed models in comparison with the previous reported literature. 
TABLE VI

GAME RESULTS AND COMPUTER WINNING PERCENTAGE IN MEN WITH MARKOV UPGRADED MODEL (C, P, AND T IS COMPUTER WINS, PLAYER WINS AND TIE, RESPECTIVELY)

\begin{tabular}{|c|c|c|c|c|c|c|c|c|}
\hline \multirow[t]{3}{*}{$\begin{array}{l}\text { Men'player } \\
\text { number }\end{array}$} & \multicolumn{6}{|c|}{ Game results } & \multicolumn{2}{|c|}{$\begin{array}{c}\text { Computer winning } \\
\text { percentage }\end{array}$} \\
\hline & \multicolumn{3}{|c|}{ With 15 rounds } & \multicolumn{3}{|c|}{ With 20 rounds } & \multirow{2}{*}{$\begin{array}{l}\text { With } 15 \\
\text { rounds }\end{array}$} & \multirow{2}{*}{$\begin{array}{l}\text { With } 20 \\
\text { rounds }\end{array}$} \\
\hline & 1 & 2 & 3 & 1 & 2 & 3 & & \\
\hline \multirow[t]{3}{*}{1} & C: 6 & $\mathrm{C}: 4$ & $\mathrm{C}: 6$ & $\mathrm{C}: 7$ & $\mathrm{C}: 9$ & $\mathrm{C}: 5$ & \multirow[t]{3}{*}{$66.66 \%$} & \multirow[t]{3}{*}{$100 \%$} \\
\hline & P: 5 & $P: 5$ & P: 0 & $P: 4$ & $P: 4$ & P: 4 & & \\
\hline & $\mathrm{T}: 4$ & $\mathrm{~T}: 6$ & $\mathrm{~T}: 9$ & $\mathrm{~T}: 9$ & $\mathrm{~T}: 7$ & $\mathrm{~T}: 11$ & & \\
\hline \multirow[t]{3}{*}{2} & C: 4 & $\mathrm{C}: 5$ & $\mathrm{C}: 2$ & $\mathrm{C}: 5$ & $C: 6$ & $C: 10$ & \multirow[t]{3}{*}{$66.66 \%$} & \multirow[t]{3}{*}{$83.33 \%$} \\
\hline & P: 3 & $P: 4$ & P: 7 & P: 5 & P: 5 & P: 3 & & \\
\hline & $\mathrm{T}: 8$ & $\mathrm{~T}: 6$ & $\mathrm{~T}: 6$ & $\mathrm{~T}: 10$ & $\mathrm{~T}: 9$ & $\mathrm{~T}: 7$ & & \\
\hline \multirow[t]{3}{*}{3} & C: 8 & $\mathrm{C}: 3$ & $\mathrm{C}: 5$ & $\mathrm{C}: 8$ & C: 10 & $\mathrm{C}: 5$ & \multirow[t]{3}{*}{$66.66 \%$} & \multirow[t]{3}{*}{$50 \%$} \\
\hline & P: 2 & P: 5 & P: 4 & P: 8 & P: 6 & P: 6 & & \\
\hline & $\mathrm{T}: 5$ & $\mathrm{~T}: 7$ & $\mathrm{~T}: 6$ & $\mathrm{~T}: 4$ & $\mathrm{~T}: 4$ & $\mathrm{~T}: 9$ & & \\
\hline \multirow[t]{3}{*}{4} & C: 7 & $\mathrm{C}: 2$ & $\mathrm{C}: 4$ & $\mathrm{C}: 6$ & C: 9 & $\mathrm{C}: 8$ & \multirow[t]{3}{*}{$50 \%$} & \multirow[t]{3}{*}{$50 \%$} \\
\hline & P: 5 & P: 8 & P: 4 & P: 8 & P: 7 & P: 8 & & \\
\hline & $\mathrm{T}: 3$ & $\mathrm{~T}: 5$ & $\mathrm{~T}: 7$ & $\mathrm{~T}: 6$ & $\mathrm{~T}: 4$ & $\mathrm{~T}: 4$ & & \\
\hline \multirow[t]{3}{*}{5} & $C: 3$ & $\mathrm{C}: 7$ & $C: 12$ & $\mathrm{C}: 9$ & $\mathrm{C}: 11$ & $\mathrm{C}: 5$ & \multirow[t]{3}{*}{$66.66 \%$} & \multirow[t]{3}{*}{$100 \%$} \\
\hline & P: 5 & P: 5 & P: 2 & P: 4 & P: 7 & P: 4 & & \\
\hline & $\mathrm{T}: 7$ & $\mathrm{~T}: 3$ & $\mathrm{~T}: 1$ & $\mathrm{~T}: 7$ & $\mathrm{~T}: 2$ & $\mathrm{~T}: 11$ & & \\
\hline \multirow[t]{3}{*}{6} & C: 5 & $\mathrm{C}: 5$ & $\mathrm{C}: 7$ & $\mathrm{C}: 6$ & $\mathrm{C}: 10$ & $\mathrm{C}: 5$ & \multirow[t]{3}{*}{$66.66 \%$} & \multirow[t]{3}{*}{$33.33 \%$} \\
\hline & P: 4 & P: 8 & P: 4 & P: 9 & P: 4 & P: 7 & & \\
\hline & $\mathrm{T}: 6$ & $\mathrm{~T}: 2$ & $\mathrm{~T}: 4$ & $\mathrm{~T}: 5$ & $\mathrm{~T}: 6$ & $\mathrm{~T}: 8$ & & \\
\hline \multirow[t]{3}{*}{7} & C: 6 & $C: 10$ & $\mathrm{C}: 9$ & $\mathrm{C}: 9$ & C: 12 & $\mathrm{C}: 8$ & \multirow[t]{3}{*}{$100 \%$} & \multirow[t]{3}{*}{$100 \%$} \\
\hline & P: 5 & P: 3 & P: 6 & P: 4 & P: 4 & P: 4 & & \\
\hline & $\mathrm{T}: 4$ & $\mathrm{~T}: 2$ & $\mathrm{~T}: 0$ & $\mathrm{~T}: 7$ & $\mathrm{~T}: 4$ & $\mathrm{~T}: 8$ & & \\
\hline 8 & C: 7 & $\mathrm{C}: 5$ & $\mathrm{C}: 7$ & $\mathrm{C}: 3$ & C: 8 & $\mathrm{C}: 9$ & $83.33 \%$ & $66.66 \%$ \\
\hline & P: 4 & P: 5 & P: 4 & P: 6 & P: 5 & P: 7 & & \\
\hline & $\mathrm{T}: 4$ & $\mathrm{~T}: 5$ & $\mathrm{~T}: 4$ & $\mathrm{~T}: 11$ & $\mathrm{~T}: 7$ & $\mathrm{~T}: 4$ & & \\
\hline 9 & C: 8 & $\mathrm{C}: 5$ & $\mathrm{C}: 4$ & $C: 11$ & $\mathrm{C}: 10$ & $\mathrm{C}: 5$ & $66.66 \%$ & $66.66 \%$ \\
\hline & P: 5 & P: 4 & P: 5 & P: 5 & P: 4 & P: 8 & & \\
\hline & $\mathrm{T}: 2$ & $\mathrm{~T}: 6$ & $\mathrm{~T}: 6$ & $\mathrm{~T}: 4$ & T: 6 & $\mathrm{~T}: 7$ & & \\
\hline 10 & C: 6 & $\mathrm{C}: 6$ & $\mathrm{C}: 2$ & $\mathrm{C}: 8$ & C: 7 & $\mathrm{C}: 7$ & $50 \%$ & $83.33 \%$ \\
\hline & P: 3 & P: 6 & P: 3 & P: 6 & P: 7 & P: 4 & & \\
\hline & $\mathrm{T}: 6$ & $\mathrm{~T}: 3$ & $\mathrm{~T}: 10$ & $\mathrm{~T}: 6$ & T: 6 & $\mathrm{~T}: 9$ & & \\
\hline
\end{tabular}

According to the comparison in Table IX and Fig. 9, it is clear that the average winning computer percentage in men and women with a RBF neural network and the upgraded Markov model presented in this paper is higher than previous studies. These results show a very good performance of these two intelligent algorithms in modeling the human mind in the game of rock-paper-scissors. It should be noted that the upgraded Markov model has a better performance in recognizing the human behavior pattern in the game of rockpaper-scissors with 20 rounds and fewer games than the RBF neural network with 50 rounds of the game, clearly, as the number of game rounds increases this model works more powerfully since its database becomes richer.

\section{VI.CONCLUSION}

Computer games in their present form are the result of the efforts and creative ideas of their inventors and creators. These kinds of games are an important phenomenon in today's world as an effective educational solution, a popular media, a tool for entertainment, and a fruitful economy. The main purpose of this study is to create an intelligent player in the game of rock-paper-scissors who can recognize the pattern
TABLE VII

GAME RESULTS AND COMPUTER WINNING PERCENTAGE IN WOMEN WITH MARKOV UPGRADED MODEL (C, P, AND T IS COMPUTER WINS, PLAYER WINS AND TIE, RESPECTIVELY)

\begin{tabular}{|c|c|c|c|c|c|c|c|c|}
\hline \multirow[t]{3}{*}{$\begin{array}{l}\text { Women's } \\
\text { player number }\end{array}$} & \multicolumn{6}{|c|}{ Game results } & \multicolumn{2}{|c|}{$\begin{array}{c}\text { Computer winning } \\
\text { percentage }\end{array}$} \\
\hline & \multicolumn{3}{|c|}{ With 15 rounds } & \multicolumn{3}{|c|}{ With 20 rounds } & \multirow{2}{*}{$\begin{array}{l}\text { With } 15 \\
\text { rounds }\end{array}$} & \multirow{2}{*}{$\begin{array}{l}\text { With } 20 \\
\text { rounds }\end{array}$} \\
\hline & 1 & 2 & 3 & 1 & 2 & 3 & & \\
\hline 1 & $\begin{array}{l}\text { C: } 4 \\
\text { P: } 3 \\
\text { T: } 8\end{array}$ & $\begin{array}{l}\text { C: } 8 \\
\text { P: } 3 \\
\text { T: } 4\end{array}$ & $\begin{array}{l}\text { C: } 6 \\
\text { P: } 3 \\
\text { T: } 6\end{array}$ & $\begin{array}{l}\text { C: } 9 \\
\text { P: } 4 \\
\text { T: } 7\end{array}$ & $\begin{array}{l}\text { C: } 5 \\
\text { P: } 7 \\
\text { T: } 8\end{array}$ & $\begin{array}{l}\text { C: } 11 \\
\text { P: } 5 \\
\text { T: } 4\end{array}$ & $100 \%$ & $66.66 \%$ \\
\hline 2 & $\begin{array}{c}\text { C: } 10 \\
\text { P: } 4 \\
\text { T: } 1\end{array}$ & $\begin{array}{l}\text { C: } 5 \\
\text { P: } 8 \\
\text { T: } 2\end{array}$ & $\begin{array}{l}\text { C: } 4 \\
\text { P: } 6 \\
\text { T: } 5\end{array}$ & $\begin{array}{c}\text { C: } 5 \\
\text { P: } 11 \\
\text { T: } 4\end{array}$ & $\begin{array}{l}\text { C: } 9 \\
\text { P: } 6 \\
\text { T: } 5\end{array}$ & $\begin{array}{l}\text { C: } 11 \\
\text { P: } 2 \\
\text { T: } 7\end{array}$ & $33.33 \%$ & $66.66 \%$ \\
\hline 3 & $\begin{array}{l}\text { C: } 4 \\
\text { P: } 3 \\
\text { T: } 8\end{array}$ & $\begin{array}{l}\text { C: } 6 \\
\text { P: } 4 \\
\text { T: } 5\end{array}$ & $\begin{array}{l}\text { C: } 9 \\
\text { P: } 2 \\
\text { T: } 4\end{array}$ & $\begin{array}{l}\text { C: } 8 \\
\text { P: } 6 \\
\text { T: } 6\end{array}$ & $\begin{array}{l}\text { C: } 15 \\
\text { P: } 3 \\
\text { T: } 2\end{array}$ & $\begin{array}{c}\text { C: } 6 \\
\text { P: } 4 \\
\text { T: } 10\end{array}$ & $100 \%$ & $100 \%$ \\
\hline 4 & $\begin{array}{l}\text { C: } 5 \\
\text { P: } 4 \\
\text { T: } 6\end{array}$ & $\begin{array}{l}\text { C: } 7 \\
\text { P: } 4 \\
\text { T: } 4\end{array}$ & $\begin{array}{l}\text { C: } 5 \\
\text { P: } 7 \\
\text { T: } 3\end{array}$ & $\begin{array}{c}\text { C: } 15 \\
\text { P: } 4 \\
\text { T: } 1\end{array}$ & $\begin{array}{l}\text { C: } 18 \\
\text { P: } 1 \\
\text { T: } 1\end{array}$ & $\begin{array}{c}\text { C: } 3 \\
\text { P: } 10 \\
\text { T: } 7\end{array}$ & $66.66 \%$ & $66.66 \%$ \\
\hline 5 & $\begin{array}{l}\text { C: } 6 \\
\text { P: } 4 \\
\text { T: } 5\end{array}$ & $\begin{array}{l}\text { C: } 6 \\
\text { P: } 3 \\
\text { T: } 6\end{array}$ & $\begin{array}{l}\text { C: } 4 \\
\text { P: } 5 \\
\text { T: } 6\end{array}$ & $\begin{array}{l}\text { C: } 9 \\
\text { P: } 6 \\
\text { T: } 5\end{array}$ & $\begin{array}{l}\text { C: } 4 \\
\text { P: } 8 \\
\text { T: } 8\end{array}$ & $\begin{array}{l}\text { C: } 8 \\
\text { P: } 7 \\
\text { T: } 5\end{array}$ & $66.66 \%$ & $66.66 \%$ \\
\hline 6 & $\begin{array}{l}\text { C: } 8 \\
\text { P: } 3 \\
\text { T: } 4\end{array}$ & $\begin{array}{c}\text { C: } 5 \\
\text { P: } 10 \\
\text { T: } 0\end{array}$ & $\begin{array}{l}\text { C: } 7 \\
\text { P: } 2 \\
\text { T: } 6\end{array}$ & $\begin{array}{l}\text { C: } 7 \\
\text { P: } 5 \\
\text { T: } 8\end{array}$ & $\begin{array}{l}\text { C: } 9 \\
\text { P: } 8 \\
\text { T: } 2\end{array}$ & $\begin{array}{l}\text { C: } 9 \\
\text { P: } 4 \\
\text { T: } 7\end{array}$ & $66.66 \%$ & $100 \%$ \\
\hline 7 & $\begin{array}{l}\text { C: } 8 \\
\text { P: } 4 \\
\text { T: } 3\end{array}$ & $\begin{array}{l}\text { C: } 7 \\
\text { P: } 4 \\
\text { T: } 4\end{array}$ & $\begin{array}{l}\text { C: } 9 \\
\text { P: } 2 \\
\text { T: } 4\end{array}$ & $\begin{array}{l}\text { C: } 10 \\
\text { P: } 6 \\
\text { T: } 4\end{array}$ & $\begin{array}{l}\text { C: } 13 \\
\text { P: } 4 \\
\text { T: } 3\end{array}$ & $\begin{array}{c}\text { C: } 4 \\
\text { P: } 6 \\
\text { T: } 10\end{array}$ & $100 \%$ & $66.66 \%$ \\
\hline 8 & $\begin{array}{l}\text { C: } 5 \\
\text { P: } 7 \\
\text { T: } 3\end{array}$ & $\begin{array}{l}\text { C: } 6 \\
\text { P: } 5 \\
\text { T: } 4\end{array}$ & $\begin{array}{l}\text { C: } 7 \\
\text { P: } 4 \\
\text { T: } 4\end{array}$ & $\begin{array}{l}\text { C: } 9 \\
\text { P: } 6 \\
\text { T: } 5\end{array}$ & $\begin{array}{l}\text { C: } 7 \\
\text { P: } 6 \\
\text { T: } 7\end{array}$ & $\begin{array}{l}\text { C: } 11 \\
\text { P: } 5 \\
\text { T: } 4\end{array}$ & $66.66 \%$ & $100 \%$ \\
\hline 9 & $\begin{array}{l}\text { C: } 3 \\
\text { P: } 5 \\
\text { T: } 7\end{array}$ & $\begin{array}{l}\text { C: } 6 \\
\text { P: } 4 \\
\text { T: } 5\end{array}$ & $\begin{array}{l}\text { C: } 8 \\
\text { P: } 3 \\
\text { T: } 4\end{array}$ & $\begin{array}{l}\text { C: } 6 \\
\text { P: } 8 \\
\text { T: } 6\end{array}$ & $\begin{array}{l}\text { C: } 8 \\
\text { P: } 3 \\
\text { T: } 9\end{array}$ & $\begin{array}{l}\text { C: } 11 \\
\text { P: } 7 \\
\text { T: } 2\end{array}$ & $66.66 \%$ & $66.66 \%$ \\
\hline 10 & $\begin{array}{l}\text { C: } 4 \\
\text { P: } 6 \\
\text { T: } 5\end{array}$ & $\begin{array}{l}\text { C: } 6 \\
\text { P: } 8 \\
\text { T: } 1\end{array}$ & $\begin{array}{l}\text { C: } 8 \\
\text { P: } 2 \\
\text { T: } 5\end{array}$ & $\begin{array}{l}\text { C: } 11 \\
\text { P: } 2 \\
\text { T: } 7\end{array}$ & $\begin{array}{l}\text { C: } 5 \\
\text { P: } 7 \\
\text { T: } 8\end{array}$ & $\begin{array}{l}\text { C: } 13 \\
\text { P: } 3 \\
\text { T: } 4\end{array}$ & $33.33 \%$ & $66.66 \%$ \\
\hline
\end{tabular}

TABLE VIII

NUMBER OF COMPUTER WINS, LOSSES, AND TIES IN 30 GAMES AMONG MEN AND WOMEN WITH MARKOV UPGRADED MODEL

\begin{tabular}{|c|c|c|c|c|c|c|}
\hline \multirow[t]{3}{*}{ Sexuality } & \multicolumn{6}{|c|}{30 games played } \\
\hline & \multicolumn{3}{|c|}{ With 15 rounds } & \multicolumn{3}{|c|}{ With 20 rounds } \\
\hline & $\begin{array}{c}\text { Computer } \\
\text { wins }\end{array}$ & $\begin{array}{c}\text { Computer } \\
\text { losses }\end{array}$ & Ties & $\begin{array}{c}\text { Computer } \\
\text { wins }\end{array}$ & $\begin{array}{c}\text { Computer } \\
\text { losses }\end{array}$ & Ties \\
\hline Men & 19 games & 8 games & 3 games & 20 games & 6 games & 4 games \\
\hline Women & 21 games & 9 games & 0 games & 23 games & 7 games & 0 games \\
\hline
\end{tabular}

TABLE IX

COMPARISON OF WINNING PERCENTAGE OF THE PROPOSED MODELS AND PREVIOUS STUDIES

\begin{tabular}{lc}
\hline \hline Pervious studies & Winning percentage \\
\hline Ali et al., 2000 & $60 \%$ \\
de Souza et al., 2013 & $70 \%$ \\
Cenggoro et al., 2014 & $40 \%$ \\
Salvetti et al., 2007 & $46 \%$ \\
Ghasemi et al., 2020 & $59 \%$ \\
Ahmadi et al., 2019 & $66 \%$ \\
Pozzato et al., 2013 & $36.65 \%$ \\
In this study with MLP neural network & $60 \%$ \\
With RBF neural network & $76.66 \%$ \\
Markov upgraded with 20 rounds & $75 \%$ \\
\hline \hline
\end{tabular}


of human behavior and defeat her/him. To achieve this, ANNs (MLP and RBF) and upgraded Markov model were used. The results showed that the percentage of winning computer with RBF neural network and upgraded Markov model, on average in men and women is $76.66 \%$ and $75 \%$. These results indicate the excellent performance of these two intelligent algorithms in detecting human behavior in the game of rock-paperscissors. It is worth to mention that the percentage of winning computer with the mentioned algorithms is higher than the percentage of computer wins without intelligent algorithms. Moreover, this game can be played against a human opponent by implementing it in the form of Zana intelligent robot together with MATLAB GUI graphical environment.

\section{REFERENCES}

Ahmadi, E., Pour, A.G., Siamy, A., Taheri, A. and Meghdari, A., 2019. Playing rock-paper-scissors with RASA: A case study on intention prediction in humanrobot interactive games. In: International Conference on Social Robotics. Springer, Cham, pp.347-357.

Ahmadvand, M.A., 1993. Game Psychology. $1^{\text {st }}$ ed. Payame Noor University, Iran.

Ali, F.F., Nakao, Z. and Chen, Y.W., 2000. Playing the rock-paper-scissors game with a genetic algorithm. In: Proceedings of the 2000 Congress on Evolutionary Computation, CEC00 (Cat. No. 00TH8512). Vol. 1. IEEE, United States, pp.741-745.

Ahmadi, E., Pour, A.G., Siamy, A., Taheri, A., Meghdari, A., 2019. Playing rockpaper-scissors with RASA: A case study on intention prediction in human-robot interactive games. In: Salichs, M.A., Ge, S.S., Barakova, E.I., Cabibihan, J.J., Wagner, A.R., Castro-González, Á., He, H., (Eds.), Social Robotics, Lecture Notes in Computer Science, ICSR 2019. Vol. 11876. Springer, Cham.

Cenggoro, T.W., Kridalaksana, A.H., Arriyanti, E. and Ukkas, M.I., 2014. Recognition of a human behavior pattern in paper rock scissor game using back propagation artificial neural network method. In: $20142^{\text {nd }}$ International Conference on Information and Communication Technology (ICoICT). IEEE, United States, pp.238-243.

Chen, W.Y., Chung, C.H., Heish, S.Y. and Ku, C.C., 2010. Rock, paper and scissors image identification scheme. In: $4^{\text {th }}$ International Conference on New Trends in Information Science and Service Science. IEEE, United States, pp.748-753.

De Caro, F., Vaccaro, A. and Villacci, D., 2019. A Markov chain-based model for wind power prediction in congested electrical grids. The Journal of Engineering, 2019(18), pp.4961-4964.

de Souza, D.F., Carneiro, H.C., França, F.M. and Lima, P.M., 2013. Rock-paperscissors WiSARD. In: 2013 BRICS Congress on Computational Intelligence and $11^{\text {th }}$ Brazilian Congress on Computational Intelligence. IEEE, United States, pp.178-182.

Dehlaghi, V., Taghipour, M., Haghparast, A., Roshani, G.H., Rezaei, A., Shayesteh, S.P., Adineh-Vand, A. and Karimi, G.R., 2015. Prediction of the thickness of the compensator filter in radiation therapy using computational intelligence. Medical Dosimetry, 40(1), pp.53-57.

Fausett, L.V., 2006. Fundamentals of Neural Networks: Architectures, Algorithms and Applications. Pearson Education, India.

Gang, T., Cho, Y. and Choi, Y., 2017. Classification of rock-paper-scissors using electromyography and multi-layer perceptron. In: $201714^{\text {th }}$ International Conference on Ubiquitous Robots and Ambient Intelligence (URAI). IEEE, United States, pp.406-407.

Ghasemi, M., Roshani, G.H. and Roshani, A., 2020. Detecting of human behavioral pattern in rock, paper, scissors game using artificial intelligence. Computational Engineering and Physical Modeling, 3(1), pp.21-30.

Hasuda, Y., Ishibashi, S., Kozuka, H., Okano, H. and Ishikawa, J., 2007. A robot designed to play the game Rock, Paper, Scissors. In: 2007 IEEE International Symposium on Industrial Electronics. IEEE, United States, pp.2065-2070.

He, J., La Croix, A.D., Wang, J., Ding, W. and Underschultz, J.R., 2019. Using neural networks and the Markov Chain approach for facies analysis and prediction from well logs in the Precipice Sandstone and Evergreen Formation, Surat Basin, Australia. Marine and Petroleum Geology, 101, pp.410-427.

Hu, W., Zhang, G., Tian, H. and Wang, Z., 2019. Chaotic dynamics in asymmetric rock-paper-scissors games. IEEE Access, 7, pp.175614-175621.

Jamshidi, M., Lalbakhsh, A., Talla, J., Peroutka, Z., Hadjilooei, F., Lalbakhsh, P., Jamshidi, M., Spada, L.L., Mirmozafari, M., Dehghani, M., Sabet, A., Roshani, S., Roshani, S., Bayat-Makou, N., Mohamadzade, B., Malek, Z., Jamshidi, A., Kiani, S., Hashemi-Dezaki, H. and Mohyuddin, W., 2020. Artificial intelligence and COVID-19: Deep learning approaches for diagnosis and treatment. IEEE Access, 8, pp.109581-109595.

Matsumoto, Y., Yamamoto, T., Honda, K., Notsu, A. and Ichihashi, H., 2012. Application of cluster validity criteria to Rock-Paper-Scissors game judgment. In: 2012 IEEE International Conference on Fuzzy Systems. IEEE, United States, pp.1-5.

Menhaj, M.B., 2008. Fundamentals of Neural Networks (Computational Intelligence). Vol. 1. Center Published of Professor Hesabi, Iran, p.715.

Nazemi, E., Roshani, G.H., Feghhi, S.A.H., Setayeshi, S. and Peyvandi, R.G., 2015. A radiation-based hydrocarbon two-phase flow meter for estimating of phase fraction independent of liquid phase density in stratified regime. Flow Measurement and Instrumentation, 46, pp.25-32.

Pozzato, G., Michieletto, S. and Menegatti, E., 2013. Towards smart robots: Rock-Paper-Scissors gaming versus human players. In: PAI@AI*IA, pp.89-95.

Roshani, G.H., Feghhi, S.A.H., Mahmoudi-Aznaveh, A., Nazemi, E. and AdinehVand, A., 2014. Precise volume fraction prediction in oil-water-gas multiphase flows by means of gamma-ray attenuation and artificial neural networks using one detector. Measurement, 51, pp.34-41.

Roshani, G.H., Nazemi, E. and Feghhi, S.A.H., 2016. Investigation of using 60Co source and one detector for determining the flow regime and void fraction in gasliquid two-phase flows. Flow Measurement and Instrumentation, 50, pp.73-79.

Roshani, G.H., Nazemi, E. and Roshani, M.M., 2017. Intelligent recognition of gas-oil-water three-phase flow regime and determination of volume fraction using Radial basis function. Flow Measurement and Instrumentation, 54, pp.39-45.

Roshani, G.H., Nazemi, E. and Roshani, M.M., 2017. Usage of two transmitted detectors with optimized orientation in order to three phase flow metering. Measurement, 100, pp.122-130.

Roshani, G.H., Roshani, S., Nazemi, E. and Roshani, S., 2018. Online measuring density of oil products in annular regime of gas-liquid two phase flows. Measurement, 129, pp.296-301.

Roshani, M., Phan, G., Faraj, R.H., Phan, N.H., Roshani, G.H., Nazemi, B., Corniani, E. and Nazemi, E., 2021. Proposing a gamma radiation based intelligent system for simultaneous analyzing and detecting type and amount of petroleum by-products. Nuclear Engineering and Technology, 2020, pp.1-7.

Roshani, M., Phan, G., Roshani, G.H., Hanus, R., Nazemi, B., Corniani, E. and Nazemi, E., 2021. Combination of X-ray tube and GMDH neural network as a nondestructive and potential technique for measuring characteristics of gas-oilwater three phase flows. Measurement, 168, p.108427.

Roshani, M., Phan, G.T., Ali, P.J.M., Roshani, G.H., Hanus, R., Duong, T., Corniani, E., Nazemi, E. and Kalmoun, E.M., 2021. Evaluation of flow pattern recognition and void fraction measurement in two phase flow independent of oil pipeline's scale layer thickness. Alexandria Engineering Journal, 60(1), pp.1955-1966.

Roshani, M., Sattari, M.A., Ali, P.J.M., Roshani, G.H., Nazemi, B., Corniani, E. and Nazemi, E., 2020. Application of GMDH neural network technique to improve measuring precision of a simplified photon attenuation based two-phase flow meter. Flow Measurement and Instrumentation, 75, p.101804.

Salvetti, F., Patelli, P. and Nicolo, S., 2007. Chaotic time series prediction for the game, Rock-Paper-Scissors. Applied Soft Computing, 7(4), pp.1188-1196. 